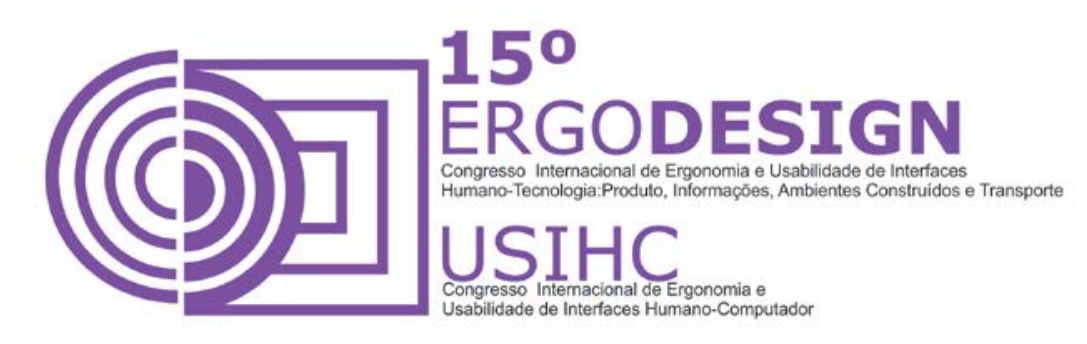

\title{
TERCEIRA IDADE E TECNOLOGIA: O POTENCIAL DO DESIGN EM PROJETOS DESTINADOS AO IDOSO
}

\section{SENIORS AND TECHNOLOGY: THE POTENTIAL OF DESIGN IN PROJECTS FOR ELDERLY}

\author{
SILVA, Andrielly Roseane (1); \\ SANTOS, Victor César Silva (2); \\ FERRO, Débora (3)
}

(1) Universidade Federal de Pernambuco, Graduanda em Design

e-mail: andriellydesign@outlook.com

(2) Universidade Federal de Pernambuco, Graduanda em Design

e-mail: victor.cesar8@hotmail.com

(3) Universidade Federal de Pernambuco, Mestre em Design

e-mail: dtferro@gmail.com

\begin{abstract}
RESUMO
Partindo de estudos relacionados ao Design Universal e à Acessibilidade, bem como ao idoso e suas necessidades, o presente artigo tem por objetivo suscitar uma reflexão sobre a demanda pela inserção do idoso no domínio tecnológico em que se encontra a sociedade contemporânea. Entendendo-se que o envelhecimento não se configura apenas como um processo genético e biológico, mas também psíquico e social, buscam-se elucidar fatores relevantes à inclusão das pessoas de terceira idade, como forma de favorecer as interfaces voltadas a este público.
\end{abstract}

Palavras-chave: Idoso; Inclusão; Tecnologia.

\begin{abstract}
Starting from studies related to Universal Design and Accessibility, as well as the elderly and their needs, this paper aims to raise a reflection about the demand for inclusion of the elderly in the field of technology on this contemporary society. Understanding that aging is not represented purely as a genetic and biological process, but also psychological and social, seek to elucidate relevant factors to the inclusion of people of old age, as a way of encouraging interfaces aimed at this public.
\end{abstract}

Keywords: Elderly, Inclusion, Technology. 


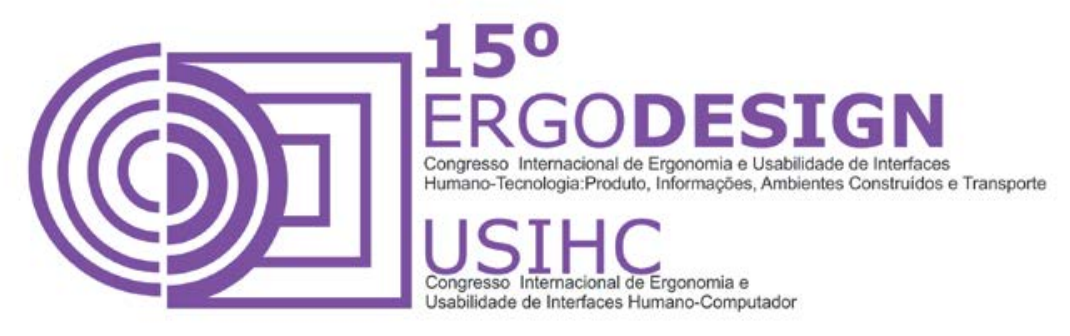

\section{INTRODUÇÃO}

Segundo dados da Organização Mundial de Saúde (OMS, 2005), o Brasil será o sexto país do mundo em quantidade de idosos até o ano de 2025. Isto já se refletia nos mais de 14,5 milhões de cidadãos brasileiros com 60 anos ou mais ainda no ano 2000.

De fato, estatísticas evidenciam que a proporção de pessoas com 60 anos ou mais está crescendo mais rapidamente que a de qualquer outra faixa etária; e com a expectativa de vida aumentando em todo planeta, na mesma proporção aumenta-se a exigência por projetos adequados a este público, cada vez mais ativo e independente.

O presente trabalho parte de uma ampla pesquisa de alunos de graduação sobre o contexto em que está inserido o público da terceira idade, tanto do ponto de vista físico, como do psíquico e social. No decorrer dos estudos, além de dados sobre as características que permeiam estes indivíduos, fez-se também o levantamento da legislação que resguarda o cidadão da terceira idade, buscando-se compreender os direitos assegurados aos mesmos e, ainda, as necessidades que se apresentam latentes nesta fase de suas vidas. Por fim, foram relacionadas as principais dificuldades encontradas pelos idosos durante o uso de recursos tecnológicos comumente disponíveis.

\section{IDOSOS E TECNOLOGIA: UMA COMPLEXA RELAÇÃO A SER COMPREENDIDA}

Apesar de dados tão contundentes quanto à expressividade do público da terceira idade, o que se percebe é que a grande parte dos projetos ainda não considera este público em potencial. E, num mundo cada vez mais tecnológico, as características físicas e psicológicas destes usuários ainda são frequentemente ignoradas, tornando quase impossível a eles realizar tarefas que parecem simples aos usuários mais jovens, em especial àqueles que já nasceram na era digital.

Não raro, observa-se a enorme dificuldade de uso de aparelhos comuns ao dia a dia, como celulares e caixas eletrônicos de bancos. Estes equipamentos digitais, que hoje permeiam o cotidiano, apresentam letras e números pequenos, bem como fazem uso de linguagens que se tornam grandes obstáculos para um grande número de idosos.

Um dos principais problemas que envolvem o sistema de interfaces entre os idosos reside na perda da acuidade visual. A visão é um dos sentidos que mais é afetado pelo envelhecimento, impactando profundamente a vida dos idosos, já que faz com que o indivíduo se torne mais dependente, mais vulnerável a perigos e, consequentemente, mais vulnerável a doenças de âmbito psicológico (RODRIGUES, 2011).

A redução capacidade auditiva, a reação mais lenta a estímulos, a diminuição da capacidade de memorizar informações, dentre outras limitações, são relevantes fatores a serem considerados.

Entende-se, portanto, que nesta difícil relação usuário-produto, é preciso considerar as perdas físicas naturais resultantes do processo de envelhecimento. Somando-se a isto, ainda há que se superar a dificuldade de aceitação daquilo que é novo por alguns usuários. Neste ponto, o Design figura como ferramenta para otimização dessas complexas interações. 


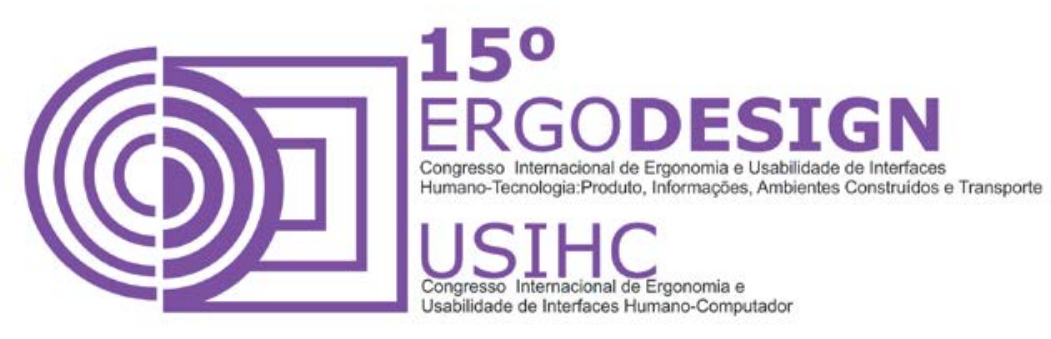

\section{O DESIGN COMO FACILITADOR DE INTERAÇÕES}

O Projeto Universal objetiva criar produtos acessíveis a todas as pessoas, independente de suas características pessoais, sensoriais, de idade, preferências e habilidades individuais. Assim, produtos universais têm a capacidade de acomodar uma larga escala de usuários, independentemente de suas dimensões, postura ou mobilidade (CAMBIAGHI, 2007).

A construção de ambientes, assim como a projetação de produtos e serviços inclusivos é tarefa do Design, o qual, através de seu aspecto criativo e inovador, é capaz de propor tecnologias acessíveis considerando as reais necessidades dos usuários em questão.

Embora, no mercado, já existam produtos extremamente funcionais direcionados aos idosos, entende-se que ainda há muito por fazer. É necessário, por exemplo, que além de se observar os aspectos funcionais, tais como números e letras maiores, haja também um apelo estético de qualidade e competitivo diante de tantas opções hoje disponibilizadas.

\section{CONCLUSÕES E CONSIDERAÇÕES FINAIS}

O presente estudo permitiu à equipe mapear as principais características do público idoso, identificando suas habilidades e limitações. Através das pesquisas, foi possível compreender fatores que dificultam a relação da terceira idade com recursos tecnológicos, em especial aqueles de ordem digital.

Os dados coletados servirão como referência para projetos voltados ao público em questão, evidenciando os elementos que caracterizam o perfil destes usuários e, assim, figurando como diferencial nos projetos direcionado à terceira idade.

A partir da identificação de fatores que influenciam o comportamento dos idosos, entende-se que é possível propor alternativas projetuais capazes de promover uma interação mais eficaz entre estes usuários e os produtos que serão desenvolvidos nesta nova fase da pesquisa.

\section{REFERÊNCIAS BIBLIOGRÁFICAS}

CAMBIAGHI, Silvana Serafino. Desenho Universal - métodos e técnicas para arquitetos e urbanistas. São Paulo: Editora Senac São Paulo, 2007.

OMS (Organização Mundial da Saúde), Envelhecimento Ativo: uma política de saúde/ World Health Organization; Tradução Suzana Gontijo. - Brasília: Organização Pan-Americana da Saúde, 2005. 60p.: il.

RODRIGUES, Ergonomia e Gerontologia face à redução da Acuidade Visual dos Idosos, Covilhã, 2011. 